\title{
Study on the optimization path of SME financing services in the context of the epidemic
}

\author{
Weijian $\mathrm{Gu}^{1}$, Rui Zhou ${ }^{1, *}$, and Jingwen Yan $^{1}$ \\ ${ }^{1}$ School of Economics, Wuhan University of Technology, Wuhan, China
}

\begin{abstract}
The status of SMEs in the national economy has become increasingly prominent, but due to the factors like their small scale, imperfect information disclosure, the problem of financing difficulty and high financing has always restricted the health of SMEs in China. This report takes Wuhan as an example, which is the earliest affected by the COVID epidemic, starting from the new financing difficulties and the development of banking business of SMEs in Wuhan under the background of the epidemic, explores the methods to guide the three parties of banks, enterprises and governments to improve services, so as to better play the role of alleviating the new financing pressure of SMEs, and puts forward some suggestions, such as promoting the interaction of government and banks' information, establishing an efficient punishment mechanism for enterprises' dishonesty, and strengthening the supervision A series of countermeasures and suggestions, such as accurate product service innovation of fast financial institutions, guiding the docking of supply chain and bill financing platform. These suggestions have important reference significance and practical reference value for better adapting to the new characteristics of financing in the post epidemic era and alleviating the financing pressure of SMEs.
\end{abstract}

\section{Introduction}

SMEs are the main force of China's economic development and the key link to enhance the stability and competitiveness of the industrial supply chain. However, the financing problem of SMEs has long plagued their healthy and stable development. Therefore, improving financing services for SMEs has been a hot topic of national importance and livelihood. In the past year, the impact of the new pneumonia epidemic has increased the pressure on SMEs' operation. "The 14th Five-Year Plan clearly points out that we should "optimize the development environment of private enterprises" and "deepen the structural reform of the financial supply side". Therefore, after the outbreak of the epidemic, how did the financing needs of SMEs change? Which aspects of SME financing are more prominent? How to improve the management of both supply and demand in order to serve SMEs and relieve their financing pressure? The solution of the above questions is of great significance to promote the long-term stable development of SMEs and deepen the supply-side reform.

\section{Overview Studies}

\subsection{Research Background}

Affected by their own small scale and imperfect information disclosure, the problem of difficult and expensive financing has always restricted the healthy development of SMEs in China. Especially after the outbreak of the new crown epidemic in 2020, the survival environment of SMEs has further deteriorated, and the production and operation activities of nearly $90 \%$ of SMEs nationwide have been seriously affected. As the earliest city affected by the epidemic, the three-monthlong city closure made the plight faced by SMEs in Wuhan even more prominent [1]. During this period, the Wuhan government and relevant financial institutions introduced a large number of emergency support and relief measures to alleviate the immediate needs of SMEs. However, with the unsealing of Wuhan and the full promotion of the epidemic prevention and control war, China has entered the "post-epidemic era", i.e., for a long period of time in the future, with the gradual stabilization of the domestic epidemic, production and business activities of enterprises gradually resume, government support is weakened, but affected by the uncertainty of the global epidemic, market supply and demand is still weak, and enterprises are facing greater operating pressure. In this context, how to cope with the new dilemma of SME financing in Wuhan in the post-epidemic era and promote the healthy development of SMEs will become the focus of this paper.

\subsection{Purpose and significance of the study}

- To explore the causes of the financing dilemma of SMEs from theoretical analysis. Through literature reading and data compilation, sort out the current academic views and

\footnotetext{
* Corresponding author: zhourui@whut.edu.cn
} 
analysis on the performance, intrinsic causes and external environment of SME financing [2].

- Investigate and analyze the new dilemma of SME financing in Wuhan City in the context of the epidemic. Based on the interaction between the government, SMEs and financial institutions, and taking into account the external influence of the epidemic, we understand the new problems and changes in the financing process of SMEs.

- To explore the optimal path to enhance information symmetry to alleviate the financing dilemma of Wuhan SMEs. Taking into account the development of banking business and changes in financing needs of SMEs in Wuhan in the post-epidemic era, we propose countermeasures to further improve the enterprise credit evaluation system, enhance corporate financial services and bank-tobank services to alleviate the new financing dilemma of SMEs in Wuhan.

\subsection{Research Methodology}

Firstly, the theories of financial exclusion and information asymmetry are integrated to analyze the causes of SMEs' financing dilemmas. Secondly, through questionnaires, field visits, platform data collection and case analysis, we obtain first-hand information on the external environment and internal demand characteristics of SME financing in Wuhan in the post-epidemic era [3]. Among them:

- The questionnaire survey mainly targets Wuhan SMEs. A total of 275 questionnaires were distributed through Wuhan SME Association, and 238 valid questionnaires were collected, with an effective rate of $86.54 \%$.

- The field visits include 5 banks (4 at municipal level and 1 at district level), 9 enterprises ( 4 in parks and 5 in non-parks), 2 parks (interviews include park managers, financial service directors and enterprise leaders), and the interview data are compiled.

\section{Theoretical analysis}

In order to help SMEs solve financing problems, it is necessary not only to find the "root cause" and "prescribe the right medicine", but also to consider the efficiency of financing. The "efficacy" of financing needs to be considered. Scholars at home and abroad have first looked at the "root of the problem" and found that the root external factor is the inadequate financial system, which has given rise to a series of problems such as information asymmetry and imbalanced credit allocation. to large enterprises with less risk, while small and medium-sized financial institutions have a close relationship with SMEs, which helps to bridge the financing gap with large enterprises. With the outbreak of the new crown epidemic, scholars have also started to pay attention to the impact of the epidemic on SME financing. Jiang Tao studied the mechanism of the impact of the epidemic on enterprise credit financing from a historical perspective and found that the epidemic increased credit demand while decreasing credit supply, thus exacerbating the gap between supply and demand in the credit market leading to a further deterioration of credit conditions. shafi et al. argued that the New crown epidemic outbreak and related business closures led to microenterprises being affected by, for example, a lack of capital, supply chain disruptions, declining demand, lower sales and profits, etc. The increase in business risk also makes it more difficult to obtain financing.

\section{Research and analysis of the current situation of financing services for small and medium-sized enterprises}

\subsection{Helpful policies to serve SME financing during the epidemic}

\subsubsection{The epidemic aggravates the financing difficulties of SMEs}

In this paper, we analyzed 275 SMEs in Wuhan through a questionnaire survey and found that $54.19 \%$ of the enterprises experienced a shrinkage of more than $20 \%$ in business income during the epidemic, with nearly $40 \%$ of the catering and accommodation enterprises experiencing a drop in income of more than $60 \%$ or even almost no income (see Figures 1-1 and 1-2). 7\% of the enterprises stopped production and their main business was greatly affected; $38 \%$ of the enterprises were affected by the shrinking market demand and orders were reduced; $17 \%$ of the enterprises' development plans were forced to be suspended due to the epidemic. affected by the contraction of market demand, with fewer orders; $17 \%$ of the enterprises' development plans were forced to suspend due to the impact of the epidemic. In addition to the information transmission enterprises, $44.53 \%$ of the enterprises had an increase in the scale of accounts receivable and a shortage of liquidity, among which the cultural, sports and entertainment industry and the catering and accommodation industry were the most obvious.

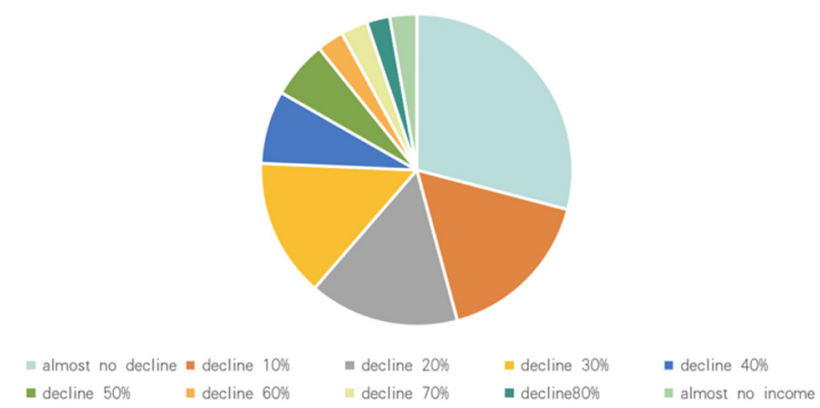

Fig. 1. Businesses affected by the epidemic business situation.

\subsubsection{Helpful policies introduced to help resume work and production}

By sorting out the relevant policies, the support policies during the epidemic in Wuhan can be mainly classified into three categories.

- The first category is special refinancing loans, which are the first batch of anti-epidemic loans promoted by the state during the epidemic, and the main targets of help are 
key enterprises related to epidemic prevention and control, such as mask production, medical services, etc. The special refinancing loans have clear target groups, more lenient loan conditions, higher approval efficiency, and the subsidy given is $50 \%$ discounted interest.

- The second category of relief loans is mainly issued through the "Hanrongtong" online integrated service platform developed by Wuhan Local Finance Bureau, with $100 \%$ interest subsidy, expected to end on March 31, 2021. The first batch of bailout loans is targeted at the manufacturing industry, with a government interest discount strategy and a ceiling of 30 million yuan per family; the second batch is not limited to industry, with a loan ceiling of 10 million yuan. In addition to this, commercial banks in Han have also taken measures such as lowering loan interest rates. In Hubei Bank, for example, the interest rate for loan placement in 2020 dropped 1.24 percentage points compared with the previous year, giving a profit of 1.67 billion yuan. Among them, the interest rate for universal micro and small loans decreased by 1.66 percentage points compared with the previous year, reducing interest expenses by more than 700 million yuan for small and micro enterprise customers.

- The third category is the credit extension policy. For SMEs whose loans expired during the epidemic and could not be repaid in time, the banks adopted a "delay as much as possible" approach, giving a grace period of more than six months to reduce the repayment pressure of SMEs. According to the data provided by Hubei Bank, in 2020, the bank implemented a total of 9,510 deferred capital repayments, amounting to 15.209 billion yuan; a total of 5,232 deferred interest payments, amounting to 1.174 billion yuan, corresponding to a loan amount of 39.227 billion yuan.

\subsection{Rising pressure on SME financing in the post -epidemic era}

\subsubsection{Support policies are gradually withdrawn and the effect of services is limited}

A series of supportive policies introduced by the government and relevant financial institutions were important support to relieve the financing pressure of SMEs during the epidemic. However, with the overall improvement of the epidemic situation, most of the relief funds are expected to stop applying on March 31, 2021, and the extended loan period is only six months. The financing pressure faced by enterprises will pick up after the relevant helping policies are phased out.

At the same time, through the analysis of some SMEs' field visits and questionnaire results, although the government has introduced a series of policies to help SMEs, but in fact the SMEs that can obtain relevant preferential loans or policy help is very limited. Various special refinancing loans have industry restrictions and are mainly used to help epidemic prevention and control enterprises to speed up production; the service targets of relief funds are mainly SMEs in various industrial parks with high credit levels, while non-park enterprises lack effective channels to understand the relief funds; although the relevant deferred repayment policies temporarily ease the repayment pressure of SMEs, they do not fundamentally solve the problem of insufficient liquidity of enterprises, moreover The relevant deferment policy, although temporarily relieving the repayment pressure of SMEs, did not fundamentally solve the problem of insufficient liquidity of enterprises, and moreover, could not solve the financing difficulties of new customers who had no financing needs but were short of funds due to the epidemic. The limited coverage of the support policy will add to the financing difficulties of SMEs in the postepidemic era. The results of the survey also show that only $5 \%$ of the 238 enterprises surveyed have actually received help.

\subsubsection{SME liquidity funding needs rise further}

As mentioned earlier, the epidemic has led to a decline in operating income and a shortage of liquidity for most SMEs. The research results show that the proportion of accounts receivable from SMEs at the upstream and downstream ends of the industry chain has increased significantly, and when the core enterprises in the industry chain are affected by the epidemic, it is difficult to pay their accounts in a timely manner, and the return of funds after delivery of orders is further slowed down. Supplementary liquidity has become the primary problem for most SMEs in the post-epidemic era.

\subsection{Financing problems of SMEs in Wuhan in the post-epidemic era are still prominent}

\subsubsection{Narrowing financing channels for SMEs}

By analyzing the capital composition of the researched enterprises, it is found that endogenous financing accounts for a relatively large proportion of these enterprises. However, the deterioration of business conditions leads to difficulties in achieving profitability in the short term, and enterprises are forced to shift their financing channels from endogenous to exogenous sources. Due to their inherent deficiencies in equity financing and debt financing, SMEs are generally highly dependent on borrowing for their exogenous financing. Once the bank side has difficulty in meeting the financing needs of SMEs, SMEs will face serious financing pressure.

\subsubsection{Bank credit services are more stringent in crediting enterprises}

After analyzing the data of 247 products on the Hanrongtong platform, this paper finds that the average interest rate of mortgage loans is around $3 \%$ and the loan size can reach millions of yuan; the interest rate of tax credit loans based on real business activities launched during the epidemic period is as high as $4.8 \%$ and the loan amount is hundreds of thousands of yuan; for catering enterprises with less tax records, the loan size is more than 10,000 yuan. For catering enterprises with less tax records, the loan amount is only about 100,000 yuan. It can be seen 
that in the post-epidemic era, in order to reduce the credit risks brought about by the poor risk resistance of SMEs, commercial banks put more emphasis on the integrity and authenticity of credit, requiring enterprises to provide "hard information" such as financial status and a high percentage of collateral, and often granting less credit and high interest rates to enterprises with little collateral and limited financial data.

\subsubsection{The cost of financing services for SMEs has risen rather than fallen}

The government and financial institutions' helping policies have provided new opportunities for bankenterprise docking, but commercial banks' lending thresholds have not been lowered, and the impact of the epidemic has led to the deterioration of SMEs' financial situation, and SMEs' credit has been squeezed. In order to obtain credit funds, SMEs had to provide a high percentage of collateral or seek guarantees from thirdparty institutions. Commercial banks, on the other hand, often spend a lot of time repeatedly collecting credit in order to obtain real information about enterprises. Therefore, although banks offer discounted loans at lower interest rates, if we consider the fees paid for seeking guarantees, the cost of information collection and the cost of time, the financing costs of SMEs do not fall, but rather rise instead of fall due to the uncertainty of the external environment.

\section{Conclusion}

The above findings tell us that firms are in urgent need of new credit data, i.e., the efficiency of the use of firm information needs to be significantly improved [4]. Therefore, this paper proposes an optimal path for SME financing services to address the information asymmetry of SMEs. Overall, the information asymmetry problem in the financing process of Chinese SMEs is caused by various aspects such as enterprises themselves, financial institute-ions and the government, so the related problems should also be solved from the following multiple perspectives. The details are as follows:

- Sound risk compensation mechanism and guarantee mechanism to serve the government-bank information docking: financial institutions can obtain information on enterprise taxation, water and electricity consumption through local industry and commerce, taxation and water and electricity departments to understand the real business situation of enterprises, or obtain information such as personal ability of enterprise managers and risk preferences through daily transactions, so as to supplement the lack of financial information of SMEs with business information and "soft" information to ease the financing pressure brought by the lack of "hard" information to SMEs.

- Establishing an efficient disciplinary mechanism for corporate default and improving the service environment of the microfinance industry: The government can sort out and integrate the normative documents related to SMEs and microfinance, improve the existing legal and regulatory system according to the market operation, establish an efficient punishment mechanism for corporate default, and reduce the risk of default in the financial market at the institutional level [5]. At the same time, the government should also actively guide SME managers to establish a sense of integrity and improve the information disclosure mechanism to reduce the occurrence of loan default, information fraud and other breach of trust.

- Standardize enterprises' own financial records and improve enterprise management services: In response to the problems of SMEs' own lack of financial information and weak credit concepts, on the basis of external conditions of restraint, SME managers should establish a sense of integrity, improve internal management, standardize enterprise financial systems and information disclosure systems, avoid falsification of accounts and misrepresentation, and fundamentally eliminate information falsification [6].

- Promote the accuracy of financial institutions' products and services to enterprises: financial institutions should, according to the different needs of SME customers, increase investment in innovation, continuously develop financial products and targeted services to meet different needs, realize the service change from "one side of a thousand enterprises" to "one thousand sides of an enterprise", improve the efficiency of loan approval, and effectively reduce the cost of enterprise financing.

\section{Acknowledgments}

This work was supported by Independent Innovation Research Fund Project of Wuhan University of Technology (2020-JJ-A1-01).

\section{References}

1. Stiglitz J.E, Weiss A. Credit Rationing in Markets with Imperfect Information[J]. The American Economic Review, 1981, 71(3): 393-410.

2. Wang, H, Feng, J. Replacing credit cramming with credit sharing - some thoughts on solving the credit imbalance between enterprises.Learning and Practice, 2018(01): 45-55.

3. Lin Y, Li Y. Small and medium-sized financial institution development and SME financing. Economic Research, 2001(01):10-18+53-93.

4. Liu C. Research on the construction of service system for small and medium-sized enterprises. Nanjing Normal University, 2017.

5. Riportella C.C, Casasola M.J, Samartin M. Do banking relationship improve credit conditions for Spanish smes? Business Economics Working Papers, 2005:1-36.

6. Shafi M, Liu J, Ren W, Impact of COVID-19 pandemic on micro, small, and medium-sized Enterprises operating in Pakistan.Research in Globalization,2020. 